\title{
Association between growth differentiation factor 5 rs 143383 genetic polymorphism and the risk of knee osteoarthritis among Caucasian but not Asian: a meta-analysis
}

Lei Peng ${ }^{1,2,3 \dagger}$, Song Jin ${ }^{1 \dagger}$, Jiping Lu ${ }^{3 \dagger}$, Chao Ouyang ${ }^{3}$, Jiang Guo ${ }^{1,2}$, Zhongyu Xie ${ }^{1,2}$, Huiyong Shen ${ }^{1,2^{*}}$ and Peng Wang ${ }^{1,2^{*}}$ (D)

\begin{abstract}
Background: A few months ago, the Bioscience Reports journal showed that growth differentiation factor 5 (GDF5) rs143383 genetic polymorphism increases the susceptibility of knee osteoarthritis (KOA), but previous studies' results have debates about available data. Considering the availability of more recent data, we focus on clarifying the relationship of KOA and GDF5 rs 143383 genetic polymorphism by a meta-analysis of case-control trial data.

Methods: The eligible studies from the time of database established to Oct. 2019 were collected from PubMed, Springer, Cochrane library, Web of Science, China National Knowledge Infrastructure (CNKI), and Wan Fang library. Odds ratios (OR) and 95\% confidence intervals $(\mathrm{Cl})$ were used to estimate the association between these polymorphisms and KOA risk. The meta-analysis was completed by STATA 18.0 software.

Results: A total of 196 studies were collected, 16 of them included in final meta-analysis (7997 cases and 12,684 controls). There was significant association between GDF5 rs143383 polymorphism and KOA in all genetic models (for Allele model ( $C$ versus T): $\mathrm{OR}=0.84(95 \% \mathrm{Cl}=0.76-0.91)$; dominate model $(C \mathrm{C}+\mathrm{CT}$ versus $\mathrm{T})$ ): $\mathrm{OR}=0.80$ (95\% $\mathrm{Cl}=0.72-0.90)$; recessive model (CC versus $\mathrm{CT}+\mathrm{TT})$ : $\mathrm{OR}=0.79(95 \% \mathrm{Cl}=0.68-0.92)$; heterozygote model $(C T$ versus $C C+T$ ): $O R=0.89$ (95\% Cl=0.80-0.97); homozygous model (CC versus TT): $\mathrm{OR}=0.71(95 \% \mathrm{Cl}=0.60-0.85)$ ). In the subgroup analysis, we obtained the results that there is no significance among Asians.
\end{abstract}

Conclusion: GDF5 rs143383 genetic polymorphism increases the risk of KOA among Caucasians; CC genotype and $\mathrm{C}$ allele are protective factors for the susceptibility of KOA among Caucasians.

Keywords: Knee osteoarthritis, Polymorphism, Growth differentiation factor 5, rs143383, Caucasian

\footnotetext{
*Correspondence: shenhuiyong@aliyun.com; wangpengsmh@foxmail.com

${ }^{\dagger}$ Lei Peng, Song Jin and Jiping Lu contributed equally to this work.

'Department of Orthopedics, The Eighth Affiliated Hospital, Sun Yat-sen

University, 3025\# Shen Nan Road, Shenzhen 518033, People's Republic of

China

Full list of author information is available at the end of the article
}

(c) The Author(s). 2020 Open Access This article is licensed under a Creative Commons Attribution 4.0 International License, which permits use, sharing, adaptation, distribution and reproduction in any medium or format, as long as you give appropriate credit to the original author(s) and the source, provide a link to the Creative Commons licence, and indicate if changes were made. The images or other third party material in this article are included in the article's Creative Commons licence, unless indicated otherwise in a credit line to the material. If material is not included in the article's Creative Commons licence and your intended use is not permitted by statutory regulation or exceeds the permitted use, you will need to obtain permission directly from the copyright holder. To view a copy of this licence, visit http://creativecommons.org/licenses/by/4.0/ The Creative Commons Public Domain Dedication waiver (http://creativecommons.org/publicdomain/zero/1.0/) applies to the data made available in this article, unless otherwise stated in a credit line to the data. 


\section{Introduction}

Osteoarthritis (OA) is a chronic degenerative disease and is a very important factor for disability in worldwide [1-3]. OA involves the knee, hip, wrist, etc. Knee osteoarthritis (KOA) is a common degenerative joint disease among osteoarthritis diseases [4]. Knee osteoarthritis is a multi-factorial disease, and its pathogenesis is currently unclear. Current studies have shown that smoking, diet, exercise, and genes are all associated with osteoarthritis [5]. The diagnosis of knee osteoarthritis is currently mainly diagnosed by imaging. There is no good way to predict the incidence of knee osteoarthritis. Recently, more and more attention has been paid to the study of knee osteoarthritis genes. It may not only explain the problem in genetics but also provide strong treatment directions for clinical workers.

Growth differentiation factor 5 (GDF5) rs143383 genetic polymorphisms is the association of the susceptibility of knee osteoarthritis reported in Bioscience Reports [5]. GDF5, also known as cartilage derived morphogenetic protein 1 (CDMP1), is an extracellular signaling molecule that participates in the development maintenance and repair of bone, cartilage, and other tissues of the synovial joint, with penetrant and rare deleterious mutations of the GDF5 gene resulting in dominant skeletal defects [6]. GDF5 is overexpressed in articular cartilage relative to osteophytic cartilage of OA patients, suggesting that it may play an important role in maintaining the stable articular chondrocyte phenotype [7].

Although the association of the risk of knee osteoarthritis and GDF5 rs143383 genetic polymorphisms has been described in several meta-analyses [8-12], several recent trials also reported the risk of knee osteoarthritis and GDF5 rs143383 genetic polymorphisms [4-6]. On the other hand, prior meta-analyses have some limitations, such as low quality and lacking enough studies. Therefore, we needed to update the data of the relevant studies and aim to clarify the relationship of GDF5 rs143383 genetic polymorphisms and the risk of knee osteoarthritis. Our article showed a latest and comprehensive relationship of GDF5 rs143383 genetic polymorphisms by using the latest and comprehensive casecontrol studies (Registered number: CRD42020168180, http://www.crd.york.ac.uk/prospero/).

\section{Methods and study designs}

The eligible studies from the time of database established to Oct. 2019 were collected from PubMed, Springer, Cochrane library, Web of Science, China National Knowledge Infrastructure (CNKI), and Wan Fang. Two independent authors extracted the data and assessed casecontrol trial quality.

In the meta-analysis, we made use of the NewcastleOttawa Scale in Epidemiology (NOS) group [13]. The
PubMed, Springer, Cochrane library, Web of Science, China National Knowledge Infrastructure (CNKI), and Wan Fang library were searched (updated to October 20, 2019) with terms "differentiation factor 5," "GDF5," "rs143383," "polymorphism," "osteoarthritis," and "OA," as both medical subject heading $(\mathrm{MeSH})$ terms and text words to find all papers that had studied the association of GDF5 with OA. A manual search was applied to finding unknown references to additional studies. English and Chinese language restrictions were applied. Studies were selected if they satisfy the following criteria: (1) case-control study; (2) sufficient published data for calculating the odds ratio and 95\% confidence interval; (3) the association of GDF5 polymorphism with OA; (4) matched Hardy-Weinberg equilibrium (HWE) in control cases; and (5) having five models' data of allelic model, homozygote model, heterozygote model, recessive model, and dominant model.

\section{Data extraction and assess of quality}

Two researchers (Lei Peng and Jiping Lu) conducted eligible studies based on the above inclusion criteria and collected information on each eligible study according to the inclusion criteria. The following items were extracted: first author, year of publication, country, population, genotype distribution, Hardy-Weinberg equilibrium (HWE), case, and control size. To avoid the wrong data, the researchers will examine the collected data and make a conclusion through discussion. The quality of studies was evaluated by two independent investigators (Peng and Lu) based on the Newcastle-Ottawa Scale (NOS) for case-control studies [14]. The study was considered high quality with the scores were $\geq 7$. In the case of disputes, we settle disputes through discussion. A third investigator (Peng Wang) decided this on the basis of discussions.

\section{Statistical methods}

Pearson's $\chi^{2}$ test estimates deviation from HWE in the control group according to genotype distributions. Crude OR with their 95\% CI was estimated and used to assess the strength of association between GDF5 rs143383 polymorphism and KOA. The pooled OR was calculated respectively for allelic effect of $C$ versus $T$, homozygote comparison of $\mathrm{CC}$ versus $\mathrm{TT}$, heterozygote comparison of $\mathrm{CT}$ versus $\mathrm{CC}+\mathrm{TT}$, recessive model $(\mathrm{CC}$ versus $\mathrm{TT}+\mathrm{CT})$ and dominant model $(\mathrm{CC}+\mathrm{CT}$ versus TT). The significance of the pooled OR was determined by the $Z$-test $(P \leq 0.05)$. $Q$ statistics $(P<0.10)$ indicated the evidence of heterogeneity was used to assess heterogeneity between studies. When significant heterogeneity was achieved $(P<0.10)$, the effect size of the study was combined with the random effect model; otherwise, the fixed effect model was used. Subgroup analysis was performed according to population, and sensitivity analysis 
was performed to determine the impact of individual studies on the aggregated results and to test the reliability of the results. The potential publishing bias was estimated by Begg's funnel plot and Egger regression test. All cases were analyzed by STATA 18.0 software (Stata Corporation, College Station, TX, USA). The $P$ values were bilateral. This study followed the PRISMA standard.

\section{Results}

\section{Studies extraction and characteristics of studies}

Sixteen articles [5, 11, 15-28], including separate 20 studies (7997 cases and 12,684 controls), finally have been collected in the meta-analysis from 196 studies, which process is showed in Fig. 1. All studies' details, including first author name, year of publication, ethnicity, country, sex, gender ration, evaluation of quality (NOS),
HWE, study design, genotyping method, and mean age, are shown in Table 1.

\section{Efficiency analysis}

By comprehensive analysis, there is significant relationship between knee osteoarthritis and GDF5 rs143383 polymorphisms. Allele model $(\mathrm{C}$ versus $\mathrm{T})$ : $\mathrm{OR}=0.84$ (95\% $\mathrm{CI}=0.76-0.92)$; dominate model $(\mathrm{CC}+\mathrm{CT}$ versus $\mathrm{TT}): \mathrm{OR}=0.80(95 \% \mathrm{CI}=0.72-0.90)$; recessive model (CC versus $\mathrm{CT}+\mathrm{TT})$ : $\mathrm{OR}=0.79(95 \% \mathrm{CI}=0.68-0.92)$; heterozygote model ( $\mathrm{CT}$ versus $\mathrm{CC}+\mathrm{TT}$ ): $\mathrm{OR}=0.88$ (95\% $\mathrm{CI}=0.80-0.96)$; homozygous model ( $\mathrm{CC}$ versus $\mathrm{TT}): \mathrm{OR}=0.88(95 \% \mathrm{CI}=0.80-0.97)$. Overall analyses are showed in Table 2. OR value of genetic model crosses 1 , which means that summary results are not of statistical significance. Summary heterogeneity of genetic

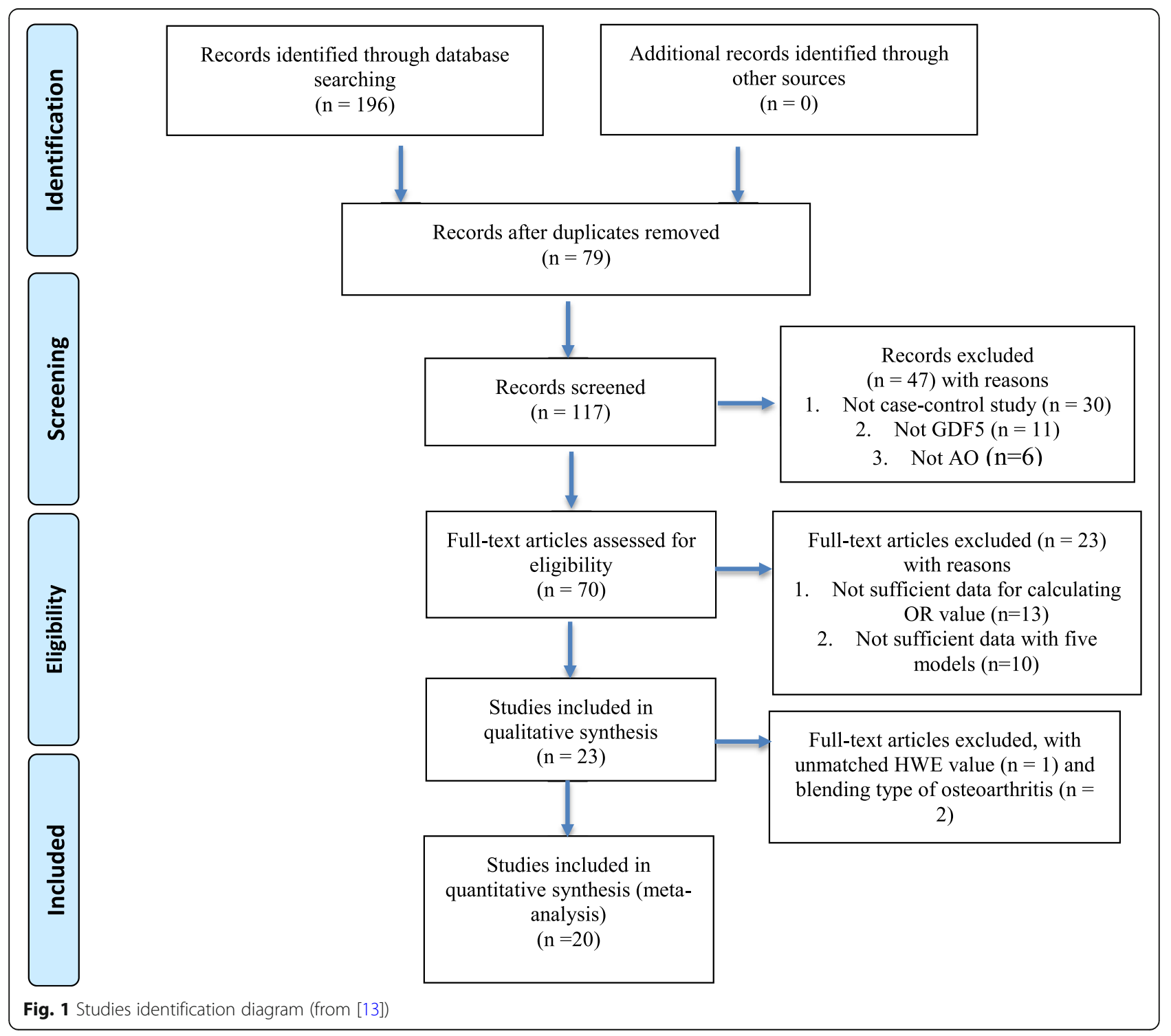


Table 1 Relevant studies concerning relationships between GDF5 rs143383 polymorphisms and knee osteoarthritis

\begin{tabular}{|c|c|c|c|c|c|c|c|c|c|}
\hline Author & Year & Country & Ethnicity & $\begin{array}{l}\text { Type of } \\
\text { disease }\end{array}$ & $\begin{array}{l}\text { Study } \\
\text { design }\end{array}$ & $\begin{array}{l}\text { Sample size of } \\
\text { case/control }\end{array}$ & $\begin{array}{l}\text { Genotyping } \\
\text { methods }\end{array}$ & $\begin{array}{l}\text { HWE among } \\
\text { controls }\end{array}$ & NOS \\
\hline Elazeem et al. [16] & 2017 & Egypt & Caucasian & $\mathrm{KOA}$ & Case-control & $50 / 50$ & Taqman & 0.58 & 8 \\
\hline Ozcan et al. [17] & 2016 & Turkey & Caucasian & $\mathrm{KOA}$ & Case-control & $94 / 279$ & PCR-RFLP & 0.06 & 8 \\
\hline Mishra et al. [15] & 2013 & India & Asian & $\mathrm{KOA}$ & Case-control & $300 / 300$ & PCR-RFLP & 0.97 & 8 \\
\hline Tawonsawatruk et al. [19] & 2011 & Thailand & Asian & $\mathrm{KOA}$ & Case-control & $90 / 103$ & PCR-RFLP & 0.63 & 8 \\
\hline Cao et al. [20] & 2010 & Korea & Caucasian & $\mathrm{KOA}$ & Case-control & $276 / 298$ & PCR-RFLP & 0.34 & 8 \\
\hline Valdes et al._-Nottingham [21] & 2009 & UK & Caucasian & $\mathrm{KOA}$ & Case-control & $735 / 654$ & Allele-specific PCR & 0.99 & 8 \\
\hline Valdes et al._Chingford [25] & 2009 & UK & Caucasian & $\mathrm{KOA}$ & Case-control & $259 / 509$ & Allele-specific PCR & 0.90 & 8 \\
\hline Tsezou et al. [22] & 2007 & Greece & Caucasian & $\mathrm{KOA}$ & Case-control & $251 / 268$ & Direct sequence & 0.66 & 8 \\
\hline Miyamoto et al._-Japan [18] & 2007 & Japan & Asian & $\mathrm{KOA}$ & Case-control & $718 / 861$ & Taqman & 0.96 & 8 \\
\hline Miyamoto et al._China [18] & 2007 & China & Asian & $\mathrm{KOA}$ & Case-control & $313 / 485$ & Taqman & 0.28 & 8 \\
\hline Southam et al._UK [23] & 2007 & UK & Caucasian & $\mathrm{KOA}$ & Case-control & $509 / 822$ & PCR-RFLP & 0.26 & 8 \\
\hline Southam et al._-Spain [23] & 2007 & Spain & Caucasian & $\mathrm{KOA}$ & Case-control & 274/1196 & Taqman & 0.54 & 8 \\
\hline Shin et al. [24] & 2012 & Korea & Asian & $\mathrm{KOA}$ & Case-control & $725 / 1737$ & $\begin{array}{l}\text { High-resolution } \\
\text { melting analysis }\end{array}$ & 0.17 & 8 \\
\hline Yao et al. [28] & 2008 & China & Asian & $\mathrm{KOA}$ & Case-control & $313 / 485$ & PCR-RFLP & 0.33 & 8 \\
\hline Vaes et al. [26] & 2009 & Netherland & Caucasian & $\mathrm{KOA}$ & Case-control & $667 / 2097$ & Taqman & 0.72 & 8 \\
\hline Zhang et al. [5] & 2019 & China & Asian & $\mathrm{KOA}$ & Case-control & 288/397 & Taqman & 0.56 & 8 \\
\hline García-Alvarado et al. [27] & 2018 & Mexico & Caucasian & $\mathrm{KOA}$ & Case-control & $145 / 145$ & RT-PCR & 0.89 & 8 \\
\hline Valdes et al.__GOAL [25] & 2011 & UK & Caucasian & $\mathrm{KOA}$ & Case-control & $867 / 758$ & Allele-specific PCR & 0.83 & 8 \\
\hline Valdes et al._-Hertfordshire [25] & 2011 & UK & Caucasian & $\mathrm{KOA}$ & Case-control & $1141 / 536$ & Allele-specific PCR & 0.22 & 8 \\
\hline Chapman et al. [11] & 2008 & Netherland & Caucasian & $\mathrm{KOA}$ & Case-control & $142 / 724$ & $\begin{array}{l}\text { Mass } \\
\text { spectrometry }\end{array}$ & 0.55 & 8 \\
\hline
\end{tabular}

model is $>50 \%$, so we conducted subgroup analysis to explain the heterogeneity.

\section{Subgroup analysis by ethnicity}

There is significant correlation between knee osteoarthritis and GDF5 rs1433383 polymorphisms in Caucasians. In Caucasians, all genetic model results are showed in Table 2 (C vs. T: OR $=0.79-0.91, P<0.05 ; \mathrm{CC}+\mathrm{CT}$ vs. TT: $\mathrm{OR}=0.71-0.92, P<0.05 ; \mathrm{CC}$ vs. CT+TT: OR = 0.72-0.90, $P<0.05$; CT vs. CC+TT: $\mathrm{OR}=0.79-1.02, P<$ 0.05 ; $\mathrm{CC}$ vs. TT: $\mathrm{OR}=0.80-1.02, P<0.05)$. But in Asians, there is no significant correlation between knee osteoarthritis and GDF5 rs143383 polymorphisms among all genetic model. We did not carry on the subgroup analysis by sex, because previous meta-analysis study conclude sex factor is not significant between GDF5 rs143383 polymorphism and the risk of knee osteoarthritis. A more obvious significant association was exploited for $\mathrm{CC}$ vs. TT+CT $(\mathrm{OR}=$ $0.81, P<0.05)$ and $C$ vs. $\mathrm{T}(\mathrm{OR}=0.84, P<0.05)$ in comparison with other models in Caucasians (Table 2, Figs. 2 and 3). The results show CC genetic model and $\mathrm{C}$ allele are protective factors in KOA. All heterogeneity of genetic model still remains. To solve the heterogeneity, we use random effect model in the meta-analysis and make sensitivity analysis to ensure reliable results.

\section{Sensitivity analysis and publication Bias}

The stableness of the results is estimated by sensitivity analysis. The sensitivity analysis procedure is a single study deleted from the meta-analysis every time, but the results remain unchanged (Fig. S1). The Begg's funnel diagram does not show any obvious sign of dissymmetry in all genetic models (Fig. 4). Furthermore, Egger's regression analysis did not show publication bias in the results $(P=0.707$ for $2 G$ versus $1 G, P=0.452$ for $2 G / 2 G$ versus $1 \mathrm{G} / 1 \mathrm{G}, P=0.452$ for $1 \mathrm{G} / 2 \mathrm{G}$ versus $1 \mathrm{G} / 1 \mathrm{G}, P=$ 0.851 for recessive model, and $P=0.133$ for dominant model, respectively). Figure 4 and Egger's regression analysis describe that results are stable and reliable in the current meta-analysis.

\section{Discussion}

In the research article, we firstly found that GDF5 rs143383 polymorphisms affect the risk of knee osteoarthritis in Caucasian but not in Asian, including detailed data from 16 studies in 7997 cases and 12,684 controls. The final results are new observations in 
Table 2 Meta-analysis for GDF5 rs 143383 polymorphisms and knee osteoarthritis risk

\begin{tabular}{|c|c|c|c|c|c|c|c|c|c|c|c|}
\hline \multirow[t]{2}{*}{ Variables } & \multirow[t]{2}{*}{$N$} & \multicolumn{2}{|l|}{ C vs T } & \multicolumn{2}{|l|}{$\mathrm{CC}+\mathrm{CT}$ vs TT } & \multicolumn{2}{|l|}{$\mathrm{CC}$ vs $\mathrm{CT}+\mathrm{TT}$} & \multicolumn{2}{|l|}{ CC vs TT } & \multicolumn{2}{|l|}{$\mathrm{CT}$ vs $\mathrm{CC}+\mathrm{TT}$} \\
\hline & & OR $(95 \% \mathrm{Cl})$ & $P_{\mathrm{h}}$ & OR $(95 \% \mathrm{Cl})$ & $P_{\mathrm{h}}$ & OR (95\% CI) & $P_{\mathrm{h}}$ & OR $(95 \% \mathrm{Cl})$ & $P_{\mathrm{h}}$ & OR $(95 \% \mathrm{Cl})$ & $P_{\mathrm{h}}$ \\
\hline \multirow[t]{2}{*}{ Total } & 20 & 0.836 & $1 \times 10^{-4}$ & 0.80 & $1 \times 10^{-4}$ & 0.79 & 0.001 & 0.88 & 0.002 & 0.88 & 0.002 \\
\hline & & $(0.76-0.91)$ & & $(0.72-0.90)$ & & $(0.68-0.92)$ & & $(0.80-0.97)$ & & $(0.80-0.96)$ & \\
\hline \multicolumn{12}{|l|}{ Ethnicity } \\
\hline \multirow[t]{2}{*}{ Asian } & 8 & 0.84 & $1 \times 10^{-4}$ & 0.80 & $1 \times 10^{-4}$ & 0.76 & 0.002 & 0.85 & 0.011 & 0.85 & 0.011 \\
\hline & & $(0.67-1.02)$ & & $(0.63-1.00)$ & & $(0.50-1.12)$ & & $(0.72-1.00)$ & & $(0.72-1.00)$ & \\
\hline \multirow[t]{2}{*}{ Caucasian } & 12 & 0.84 & 0.12 & 0.81 & $1 \times 10^{-4}$ & 0.81 & 0.92 & 0.90 & 0.013 & 0.89 & 0.016 \\
\hline & & $(0.79-0.91)$ & & $(0.71-0.92)$ & & $(0.72-0.90)$ & & $(0.80-1.02)$ & & $(0.79-1.02)$ & \\
\hline
\end{tabular}

$N$ number of studies

$P_{\mathrm{h}}$ value of $Q$-test for heterogeneity test. Random-effects model was used when $p$ value for heterogeneity test $<0.05$; otherwise, fix-effects model was used

previous studies. When carrying on the funnel plot to analyze some bias, the results still are very stable and reliable.

GDF5 is a member of bone morphogenetic proteins (BMP) family, which is located on chromosome 20q11.2 and spans $21.43 \mathrm{~kb}$, from $34,042,573$ to $34,021,146$ and can form the earliest markers of joint morphology. BMP is an indispensable signal pathway molecule or protein in most kinds of bones [29-37]. There are many cells expressing the GDF5 gene, including articular cartilage,

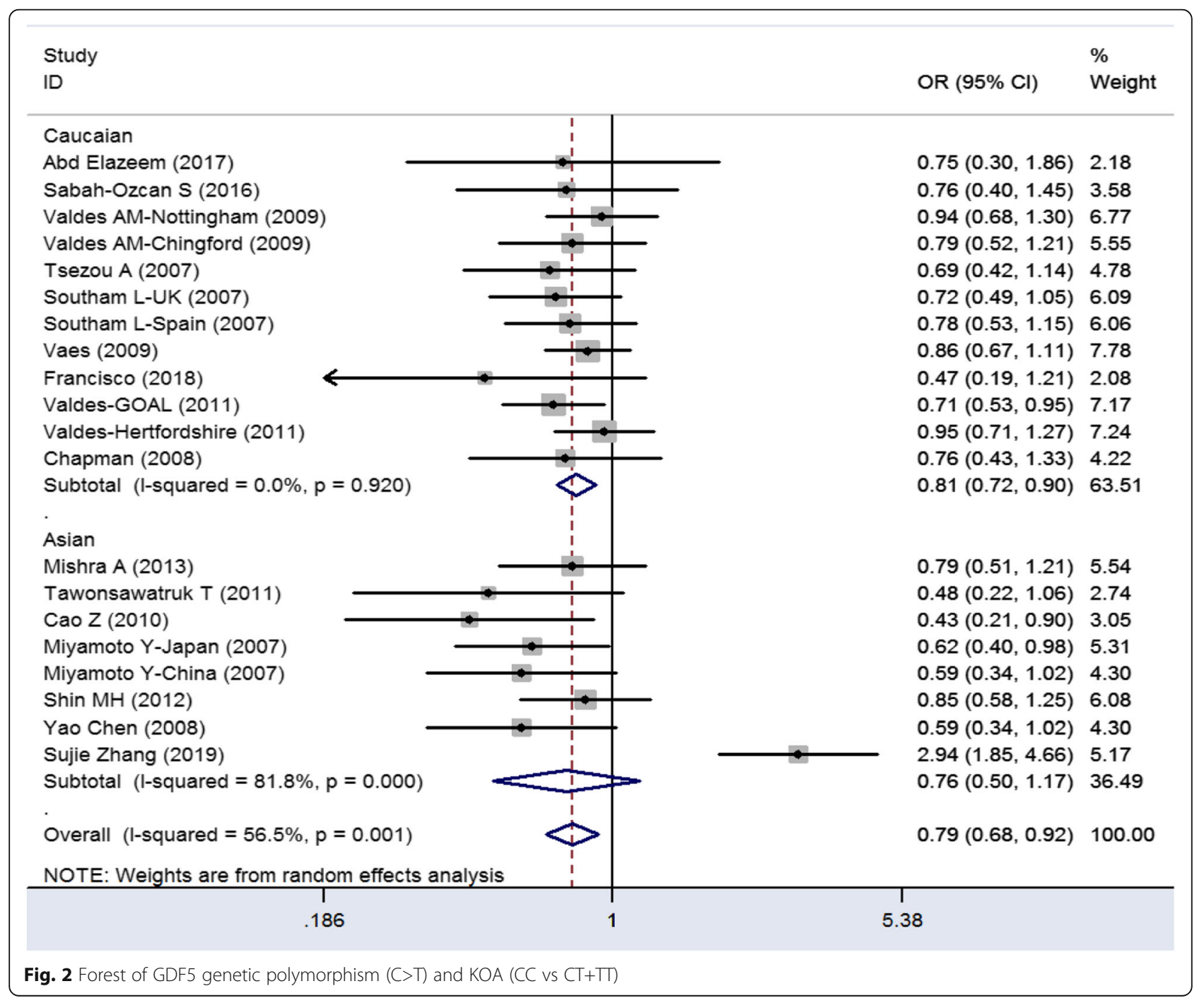




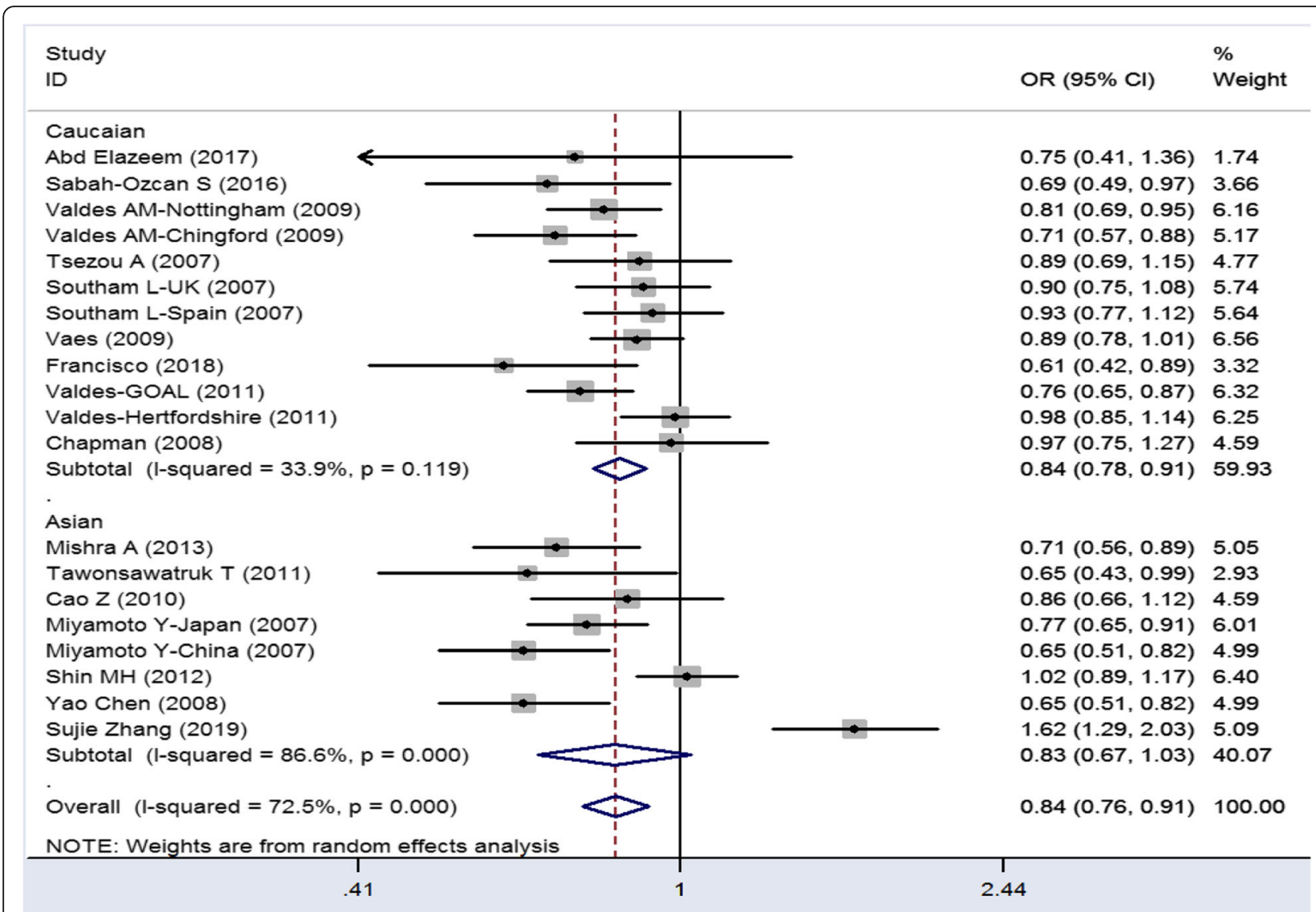

Fig. 3 Forest of GDF5 genetic polymorphism (C>T) and KOA (C vs T)

articular capsule, and ligament. GDF5 gene mutation may result in the downregulation of the transcription activity of articular chondrocytes [38-40]. Decreased GDF5 levels in fully formed adult knees may also influence OA risk by impairing homeostasis in healthy joints or by accelerating degeneration due to injury [41]. The growth differentiation factor 5 gene GDF5 was one of the first reported OA susceptibility signals that showed consistent association to $\mathrm{OA}$, with the transcript single nucleotide polymorphism (SNP) rs143383 demonstrating association in Asians and Europeans [42].

On the one hand, previous literatures have said that GDF5 rs143383 polymorphisms C allele is a protective factor for the susceptibility of knee osteoarthritis among Caucasian populations $(\mathrm{OR}=0.74, P<0.001)$ and Asian populations $(\mathrm{OR}=0.87, P=0.004)$ [9]. On the other hand, Zhang et al. holds that interaction of GDF5 rs143383 polymorphisms $\mathrm{T}$ allele increases the risk of knee osteoarthritis among Asian $(\mathrm{OR}=1.62, P<0.001)$ [5]. But now our research shows that GDF5 rs143383 polymorphisms are only related to knee osteoarthritis among Caucasian populations by subgroup analysis, not Asian populations.
Although previous meta-analysis literatures thought that high-expressed GDF5 rs143383(C/T) can reduce the risk of knee osteoarthritis, their limitations still remain. Firstly, Pan et al.'s meta-analysis has some shortcomings, including unmatching HWE studies in their metaanalysis [8], which results are unreliable. Secondly, Huang et al.'s meta-analysis explores the association between all kinds of osteoarthritis and GDF5 rs143383 polymorphisms, which cannot precisely describe the relationship between GDF5 rs143383 polymorphisms and the susceptibility of knee osteoarthritis [12]. Although genetic variants can have different effect sizes in different populations, as is shown for GDF5 for African populations vs Eurasian populations [43-45], it is highly unlikely that this is the case, based on the data presented by the authors. These studies focused on apes, so there is still a gap between apes and humans. In the discussion, the authors state that future studies should include more samples and examine more genetic variants. We did not use freely available data from large population association studies (GWAS) which have been published [46-49], because the data of the sample size of the five models cannot be extracted. The meta-analysis mainly 

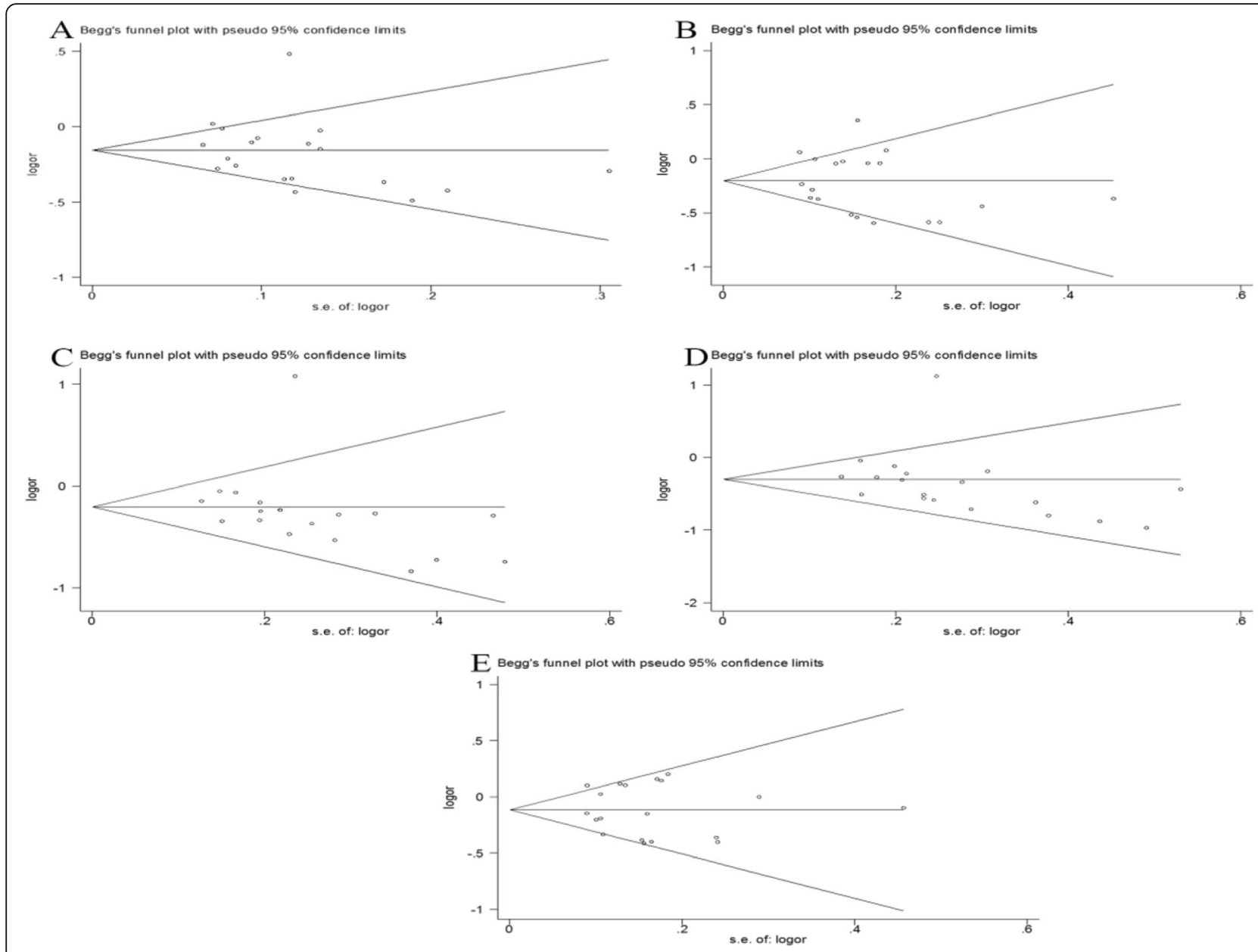

Fig. 4 Funnel plots of the association between GDF5 rs 143383 polymorphism and knee osteoarthritis (a allele model, b dominate model, c recessive model, $\mathbf{d}$ homozygote model, e heterozygote model)

focused on GDF5 rs143383, and no other variants of GDF5, because our aim is to solely clarify controversial GDF5 rs143383.

To sum it up, our final results, paralleling to previous results, are more reliable by comprehensive collection and assessment of quality. Furthermore, the association between osteoarthritis and GDF5 is more clear than previous studies.

\section{Conclusions}

Our article has found sufficient pieces of evidences to conclude that the risk of Caucasian's knee osteoarthritis is the association with GDF5 rs143383 polymorphisms. To our knowledge, this result is the first discovery in which the risk of Asian knee osteoarthritis is not associated with GDF5 rs143383 polymorphisms by metaanalysis. The finding may indicate that GDF5 rs143383 polymorphism mutations are population specific. In the future, the potential study should increase more samples about knee osteoarthritis and more gene variants to precisely and comprehensively clarify the relationship between knee osteoarthritis and gene variants.

\section{Supplementary information}

Supplementary information accompanies this paper at https://doi.org/10. 1186/s13075-020-02306-9.

Additional file 1: Fig. S1. Sensitivity analysis of the pooled ORs and 95\% Cl for the overall analysis.

\section{Abbreviations}

Cl: Confidence interval; HWE: Hardy-Weinberg equilibrium; KOA: Knee osteoarthritis; GDF: Growth differentiation factor; NOS: Newcastle-Ottawa

Scale; OA: Osteoarthritis; OR: Odds ratio; BMP: Bone morphogenetic protein

\section{Acknowledgements}

We thank LU Jiping, JIN Song, and WANG Peng for the assistance with the collection of data and genetic details for this study.

\section{Authors' contributions}

L.P. and P. W. designed the meta-analysis. L. P., J. L., C. O., and J. G. searched aimed studies and extracted corresponding data. All authors helped prepare the manuscript and approved the manuscript for submission. 


\section{Funding}

This study is supported by National Natural Science Foundation of China, Nos.81672097, 81672128, and 81702120.

\section{Availability of data and materials}

The datasets used and/or analyzed during the current study are available from the corresponding author on reasonable request.

\section{Ethics approval and consent to participate}

Not applicable.

\section{Consent for publication}

Not applicable.

\section{Competing interests}

The authors declare that there are no competing interests associated with the article.

\section{Author details China. \\ Received: 30 June 2020 Accepted: 31 August 2020 \\ Published online: 14 September 2020}

${ }^{1}$ Department of Orthopedics, The Eighth Affiliated Hospital, Sun Yat-sen University, 3025\# Shen Nan Road, Shenzhen 518033, People's Republic of China. ${ }^{2}$ Department of Orthopedics, The Second Affiliated Hospital, Sun Yat-sen University, 107\# Yan Jiang Road West, Guangzhou 510120, People's Republic of China. ${ }^{3}$ Department of Orthopedics, The Second Affiliated Hospital of Hunan Normal University, The 921 Central Hospital of the People's Liberation Army, Hongshan bridge, Changsha, People's Republic of

\section{References}

1. Gregori D, et al. Association of pharmacological treatments with long-term pain control in patients with knee osteoarthritis: a systematic review and meta-analysis. JAMA. 2018:320(24):2564-79.

2. Mokdad AH, et al. The state of US health, 1990-2016: burden of diseases, injuries, and risk factors among US states. JAMA. 2018;319(14):1444-72.

3. Glyn-Jones S, et al. Osteoarthritis. Lancet. 2015;386(9991):376-87.

4. Peng $L$, et al. Lack of association between matrix metalloproteinase-1 gene rs1799750 polymorphism and osteoarthritis susceptibility: a meta-analysis. Biosci Rep. 2019;39(4). https://doi.org/10.1042/BSR20181960.

5. Zhang S, et al. Interaction between GDF5 gene polymorphisms and environment factors increased the risk of knee osteoarthritis: a case-control study. Biosci Rep. 2019;39(2). https://doi.org/10.1042/BSR20182423.

6. Dodd AW, et al. Deep sequencing of GDF5 reveals the absence of rare variants at this important osteoarthritis susceptibility locus. Osteoarthr Cartil. 2011;19(4):430-4

7. Gelse K, et al. Molecular differentiation between osteophytic and articular cartilage--clues for a transient and permanent chondrocyte phenotype. Osteoarthr Cartil. 2012;20(2):162-71.

8. Pan F, et al. Association between GDF5 rs143383 polymorphism and knee osteoarthritis: an updated meta-analysis based on 23,995 subjects. BMC Musculoskelet Disord. 2014;15:404.

9. Jiang D, et al. Association between GDF5 +104T/C polymorphism and knee osteoarthritis in Caucasian and Asian populations: a meta-analysis based on case-control studies. J Orthop Surg Res. 2016;11(1):104.

10. Mouallem M, et al. A man with a prosthetic valve, anaemia, fever, and splenomegaly. Lancet. 1996;348(9036):1216.

11. Chapman $\mathrm{K}$, et al. A meta-analysis of European and Asian cohorts reveals a global role of a functional SNP in the 5' UTR of GDF5 with osteoarthritis susceptibility. Hum Mol Genet. 2008;17(10):1497-504.

12. Huang $X$, Zhang W, Shao Z. Association between GDF5 rs143383 genetic polymorphism and musculoskeletal degenerative diseases susceptibility: a meta-analysis. BMC Med Genet. 2018;19(1):169.

13. Moher D, et al. Preferred reporting items for systematic reviews and metaanalyses: the PRISMA statement. PLoS Med. 2009;6(7):e1000097.

14. Stang A. Critical evaluation of the Newcastle-Ottawa scale for the assessment of the quality of nonrandomized studies in meta-analyses. Eur J Epidemiol. 2010;25(9):603-5.
15. Mishra A, et al. Association of polymorphism in growth and differentiation factor 5 gene with osteoarthritis knee. Am J Biochem Biotechnol. 2013;91. https://doi.org/10.5152/eurjrheum.2017.160093.

16. Abd Elazeem Ml, Abdelaleem EA, Mohamed RA. Genetic influence of growth and differentiation factor 5 gene polymorphism (+104T/C) on the development of knee osteoarthritis and its association with disease severity. Eur J Rheumatol. 2017;4(2):98-103.

17. Ozcan SS, et al. Polymorphisms in the growth differentiation factor 5 (GDF 5) gene in knee osteoarthritis. J Coll Physicians Surg Pak. 2017; 27(10):602-5.

18. Miyamoto $Y$, et al. A functional polymorphism in the $5^{\prime}$ UTR of GDF5 is associated with susceptibility to osteoarthritis. Nat Genet. 2007:39(4):529-33.

19. Tawonsawatruk T, et al. A genetic association study between growth differentiation factor 5 (GDF 5) polymorphism and knee osteoarthritis in Thai population. J Orthop Surg Res. 2011;6:47.

20. Cao Z, et al. Growth differentiation factor 5 (GDF5) core promoter polymorphism is not associated with susceptibility to osteoarthritis of the knee in the Korean population. J Pathol Transl Med. 2010;44(4): 404-9.

21. Valdes AM, et al. Association of the DWWA and GDF5 polymorphisms with osteoarthritis in UK populations. Ann Rheum Dis. 2009;68(12):1916-20.

22. Tsezou A, et al. The growth differentiation factor 5 (GDF5) core promoter polymorphism is not associated with knee osteoarthritis in the Greek population. J Orthop Res. 2008;26(1):136-40.

23. Southam $L$, et al. An SNP in the 5'-UTR of GDF5 is associated with osteoarthritis susceptibility in Europeans and with in vivo differences in allelic expression in articular cartilage. Hum Mol Genet. 2007;16(18):2226-32.

24. Shin $\mathrm{MH}$, et al. Genetic association analysis of GDF5 and ADAM12 for knee osteoarthritis. Joint Bone Spine. 2012;79(5):488-91.

25. Valdes AM, et al. The GDF5 rs 143383 polymorphism is associated with osteoarthritis of the knee with genome-wide statistical significance. Ann Rheum Dis. 2011;70(5):873-5.

26. Vaes RB, et al. Genetic variation in the GDF5 region is associated with osteoarthritis, height, hip axis length and fracture risk: the Rotterdam study. Ann Rheum Dis. 2009;68(11):1754-60.

27. García-Alvarado F, et al. Association between the SNP rs143383 + 104T/C in the GDF5 gene and the risk of knee osteoarthritis in a population from northern Mexico-a case-control study. Genet Test Mol Biomarkers. 2018; 22(8):503-6.

28. Yao C, Dai J, Qin J. A single nucleid polymorphisms (SNP) in the $5^{\prime} U T R$ of GDF5 is associated with knee osteoarthritis. Jiangsu Med J. 2008:4(012): 1198-9.

29. Francis-West $\mathrm{PH}$, et al. Mechanisms of GDF-5 action during skeletal development. Development. 1999;126(6):1305-15.

30. Urist MR. Bone morphogenetic protein: the molecularization of skeletal system development. J Bone Miner Res. 1997;12(3):343-6.

31. Wozney JM, Rosen V. Bone morphogenetic protein and bone morphogenetic protein gene family in bone formation and repair. Clin Orthop Relat Res. 1998:346:26-37.

32. Storm EE, et al. Limb alterations in brachypodism mice due to mutations in a new member of the TGF beta-superfamily. Nature. 1994;368(6472):639-43.

33. Chang SC, et al. Cartilage-derived morphogenetic proteins. New members of the transforming growth factor-beta superfamily predominantly expressed in long bones during human embryonic development. J Biol Chem. 1994;269(45):28227-34.

34. Storm EE, Kingsley DM. Joint patterning defects caused by single and double mutations in members of the bone morphogenetic protein (BMP) family. Development. 1996;122(12):3969-79.

35. Brunet $L J$, et al. Noggin, cartilage morphogenesis, and joint formation in the mammalian skeleton. Science. 1998:280(5368):1455-7.

36. Merino $\mathrm{R}$, et al. Expression and function of Gdf-5 during digit skeletogenesis in the embryonic chick leg bud. Dev Biol. 1999;206(1):33-45.

37. Hartmann C, Tabin CJ. Wnt-14 plays a pivotal role in inducing synovial joint formation in the developing appendicular skeleton. Cell. 2001;104(3):341-51.

38. Rountree $\mathrm{RB}$, et al. BMP receptor signaling is required for postnatal maintenance of articular cartilage. PLoS Biol. 2004;2(11):e355.

39. Koyama E, et al. A distinct cohort of progenitor cells participates in synovial joint and articular cartilage formation during mouse limb skeletogenesis. Dev Biol. 2008:316(1):62-73.

40. Egli RJ, et al. Functional analysis of the osteoarthritis susceptibility-associated GDF5 regulatory polymorphism. Arthritis Rheum. 2009;60(7):2055-64. 
41. Pregizer SK, et al. Impact of broad regulatory regions on Gdf5 expression and function in knee development and susceptibility to osteoarthritis. Ann Rheum Dis. 2018;77(3):450

42. Ratnayake $\mathrm{M}$, et al. A consistent and potentially exploitable response during chondrogenesis of mesenchymal stem cells from osteoarthritis patients to the protein encoded by the susceptibility gene GDF5. PLoS One. 2017;12(5): e0176523.

43. Lewis $\mathrm{CM}$, Knight J. Introduction to genetic association studies. Cold Spring Harb Protoc. 2012;2012(3):297-306.

44. Richard D, et al. Evolutionary selection and constraint on human knee chondrocyte regulation impacts osteoarthritis risk. Cell. 2020;181(2):362-381.e28.

45. Capellini TD, et al. Ancient selection for derived alleles at a GDF5 enhancer influencing human growth and osteoarthritis risk. Nat Genet. 2017:49(8): 1202-10.

46. Tachmazidou I, et al. Identification of new therapeutic targets for osteoarthritis through genome-wide analyses of UK Biobank data. Nat Genet. 2019:51(2):230-6.

47. Zengini E, et al. Genome-wide analyses using UK Biobank data provide insights into the genetic architecture of osteoarthritis. Nat Genet. 2018;50(4): 549-58.

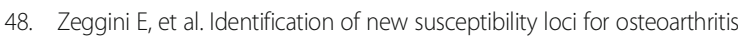
(arCOGEN): a genome-wide association study. Lancet. 2012;380(9844):815-23.

49. Styrkarsdottir U, et al. Meta-analysis of Icelandic and UK data sets identifies missense variants in SMO, IL11, COL11A1 and 13 more new loci associated with osteoarthritis. Nat Genet. 2018;50(12):1681-7.

\section{Publisher's Note}

Springer Nature remains neutral with regard to jurisdictional claims in published maps and institutional affiliations.

Ready to submit your research? Choose BMC and benefit from:

- fast, convenient online submission

- thorough peer review by experienced researchers in your field

- rapid publication on acceptance

- support for research data, including large and complex data types

- gold Open Access which fosters wider collaboration and increased citations

- maximum visibility for your research: over $100 \mathrm{M}$ website views per year

At BMC, research is always in progress.

Learn more biomedcentral.com/submissions 